\title{
The right ventricular response to lung resection
}

Philip J. McCall, MD, MBChB,,${ }^{\mathrm{a}, \mathrm{b}}$ Alex Arthur, MBChB, ${ }^{\mathrm{a}, \mathrm{b}}$ Adam Glass, MBBCh, BAO,,${ }^{\mathrm{a}, \mathrm{b}}$

David S. Corcoran, MBChB, ${ }^{c, d}$ Alan Kirk, MBChB, ${ }^{e}$ Alistair Macfie, MBChB, ${ }^{b}$ John Payne, MD, MBChB, ${ }^{f}$ Martin Johnson, MD, MBChB, ${ }^{g}{ }^{J}$ ohn Kinsella, MD, MBChB,${ }^{a}$ and Benjamin G. Shelley, MD, MBChB ${ }^{a, b}$

\section{ABSTRACT}

Objectives: Lung cancer is a leading cause of cancer death and in suitable cases the best chance of cure is offered by surgery. Lung resection is associated with significant postoperative cardiorespiratory morbidity, with dyspnea and reduced functional capacity as dominant features. These changes are poorly associated with deterioration in pulmonary function and a potential role of right ventricular (RV) dysfunction has been hypothesized. Cardiovascular magnetic resonance imaging is a reference method for noninvasive assessment of RV function and has not previously been applied to this population.

Methods: We used cardiovascular magnetic resonance imaging to assess the RV response to lung resection. Cardiovascular magnetic resonance imaging with volume and flow analysis was performed on 27 patients preoperatively, on postoperative day 2 and at 2 months. Left ventricular ejection fraction and RV ejection fraction, the ratio of stroke volume to end systolic volume, pulmonary artery acceleration time, and distensibility of main and branch pulmonary arteries were studied.

Results: Mean \pm standard deviation RV ejection fraction deteriorated from $50.5 \% \pm 6.9 \%$ preoperatively to $45.6 \% \pm 4.5 \%$ on postoperative day 2 and remained depressed at $44.9 \% \pm 7.7 \%$ by 2 months $(P=.003)$. The ratio of stroke volume to end systolic volume deteriorated from median 1.0 (quartile 1, quartile 3: $0.9,1.2$ ) preoperatively to median 0.8 (quartile 1 , quartile $3: 0.7,1.0$ ) on postoperative day $2(P=.011)$. On postoperative day 2 there was a decrease in pulmonary artery acceleration time and operative pulmonary artery distensibility $(P<.030$ for both). There were no changes in left ventricular ejection fraction during the study period $(P=.621)$.

Conclusions: These findings suggest RV dysfunction occurs following lung resection and persists 2 months after surgery. The deterioration in the ratio of stroke volume to end systolic volume suggests a mismatch between afterload and contractility. There is an increase in indices of pulsatile afterload resulting from the operative pulmonary artery. (J Thorac Cardiovasc Surg 2019;158:556-65)

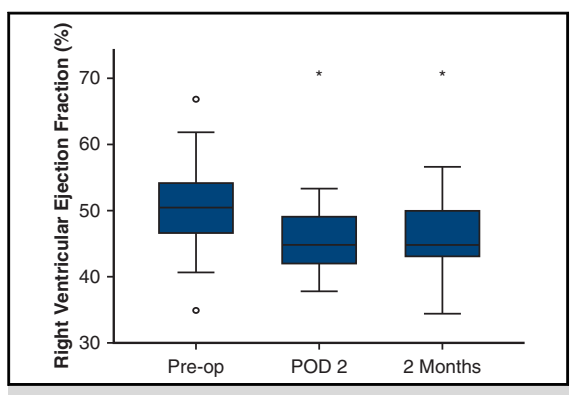

Right ventricular function deteriorates following lung resection and remains depressed 2 months postoperatively.

\section{Central Message}

$\mathrm{RV}$ ejection fraction is reduced immediately following lung resection. These changes are still present at 2 months, suggesting perioperative changes in RV function may have an influence long into the recovery period.

\section{Perspective}

There is growing interest in the role of $\mathrm{RV}$ dysfunction in cardiorespiratory morbidity following lung resection. Using cardiovascular magnetic resonance imaging, this study demonstrates postoperative RV dysfunction with increased pulsatile afterload, predominantly arising from the operative pulmonary artery. The deterioration in RV function may provide a therapeutic target for future interventions seeking to ameliorate the burden of morbidity in this population.

See Commentaries on pages 566 and 568 .
From the ${ }^{\text {a Academic }}$ Unit of Anaesthesia, Pain, and Critical Care, and ${ }^{\mathrm{c} I n s t i t u t e}$ of Cardiovascular and Medical Sciences, University of Glasgow, Glasgow, United Kingdom; and the Departments of ${ }^{\mathrm{b}}$ Anaesthesia, ${ }^{\mathrm{d}}$ Cardiology, and ${ }^{\mathrm{e}}$ Thoracic Surgery, the ${ }^{\mathrm{f}}$ National Advanced Heart Failure Service, and the ${ }^{\mathrm{g}}$ Scottish Pulmonary Vascular Unit, Golden Jubilee National Hospital, Clydebank, United Kingdom. Supported by the 2012 Association for Cardiothoracic Anaesthesia and Critical Care Project Grant. Dr Corcoran is supported by a British Heart Foundation Clinical Research Training Fellowship (FS/14/15/30661) and Dr Shelley is supported by a National Health Service Research Scotland/Chief Scientists Office Career Research Fellowship.

Received for publication June 18, 2018; revisions received Jan 16, 2019; accepted for publication Jan 19, 2019; available ahead of print Feb 28, 2019.

Address for reprints: Philip J. McCall, MD, MBChB, Academic Unit of Anaesthesia,

Pain, and Critical Care, University of Glasgow, Room 2.73, New Lister Building,

Glasgow G46 6JP United Kingdom (E-mail: philipmccall@nhs.net).

$0022-5223 / \$ 36.00$

Copyright (c) 2019 by The American Association for Thoracic Surgery

https://doi.org/10.1016/j.jtcvs.2019.01.067
Lung resection is associated with high cardiorespiratory complication rates $^{1,2}$ and significant long-term morbidity, with many patients experiencing disabling dyspnea and decreased functional capacity. ${ }^{3,4}$ These changes are poorly associated with lung function, ${ }^{5,6}$ and may be influenced by cardiac limitation. ${ }^{7,8}$ Given their close relationship, complex interaction, and potential for

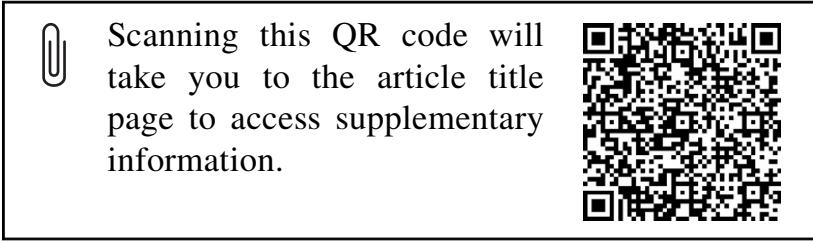




\author{
Abbreviations and Acronyms \\ $\mathrm{BNP}=\mathrm{B}$-type natriuretic peptide \\ $\mathrm{CMR}=$ cardiovascular magnetic resonance \\ $\mathrm{CO}=$ cardiac output \\ $\mathrm{CV}=$ coefficient of variation \\ $\mathrm{ESV}=$ end systolic volume \\ hsTnT $=$ high-sensitivity troponin $\mathrm{T}$ \\ $\mathrm{LV}=$ left ventricular \\ PA = pulmonary artery \\ PAAT $=$ pulmonary artery acceleration time \\ $\mathrm{POD}=$ postoperative day \\ PVR = pulmonary vascular resistance \\ $\mathrm{RV} \quad=$ right ventricular \\ $\mathrm{RVEF}=$ right ventricular ejection fraction \\ $\mathrm{SV}=$ stroke volume
}

disruption during lung resection, previous work has focused on the right ventricular (RV)/pulmonary vascular unit.

Several studies have described a $15 \%$ to $25 \%$ relative reduction in RV ejection fraction (RVEF) following lung resection $^{9-14}$; patients experiencing a greater decline in $\mathrm{RV}$ function are more likely to experience postoperative complications. ${ }^{12-14}$ Lewis and colleagues ${ }^{11}$ demonstrated that impaired RV function intraoperatively identified patients in whom late cardiorespiratory symptoms would develop, suggesting perioperative RV dysfunction has an influence long into the postoperative period.

Assessing RV function is challenging because of the RV's complex geometry, retrosternal position, and marked load dependence. ${ }^{15-17}$ Previous studies in this population have been hampered by the limitations of the techniques used (mainly volumetric PA catheters) ${ }^{9,11,18}$; in many cases, leading to conflicting results. The validity of volumetric PA catheters has been challenged, with the observation that their accuracy has never been convincingly demonstrated. ${ }^{19,20}$

The primary mechanism of RV dysfunction following lung resection is hypothesized to result from increased afterload. ${ }^{11,12,18}$ Although this seems intuitive, studies measuring pulmonary vascular resistance (PVR), as an index of RV afterload, have been unable to demonstrate sustained changes postoperatively. PVR rises intraoperatively, during single-lung ventilation and on PA clamping, but returns to baseline by 24 hours..$^{10,18,21}$ Whilst PVR is commonly used in clinical practice, this measure of opposition to mean flow (static afterload) ignores the pulsatile component of afterload. ${ }^{17} \mathrm{Up}$ to half of the hydraulic power in the main PA is contained in the pulsatile components of flow, comprising resistance, capacitance, inertia, and pulse wave reflection. As such, true RV
TABLE 1. Patient characteristics $(\mathbf{N}=\mathbf{2 7})$

\begin{tabular}{|c|c|}
\hline Characteristic & Result \\
\hline Age (y) & $67.0(59.0,74.0)$ \\
\hline Female & $17(63.0)$ \\
\hline \multicolumn{2}{|l|}{ Smoking } \\
\hline None & $2(7.4)$ \\
\hline Former & $12(44.4)$ \\
\hline Active & $13(48.1)$ \\
\hline \multicolumn{2}{|l|}{ Preoperative pulmonary function } \\
\hline $\mathrm{SaO}_{2}$ on air $(\%)$ & $96.4(1.7)$ \\
\hline $\mathrm{FEV}_{1}(\mathrm{~L})$ & $1.9(1.6,2.4)$ \\
\hline Predicted $\mathrm{FEV}_{1}(\%)$ & $87.5(25.1)$ \\
\hline $\mathrm{FEV}_{1}: \mathrm{FVC}(\%)$ & $64.1(14.8)$ \\
\hline $\mathrm{TLCO}(\mathrm{mmol} / \mathrm{kPa} / \mathrm{min})$ & $5.2(1.7)$ \\
\hline Predicted TLCO $(\%)$ & $66.6(15.2)$ \\
\hline \multicolumn{2}{|l|}{ Operative Variables } \\
\hline Pneumonectomy & $1(3.7)$ \\
\hline Lobectomy & $22(81.5)$ \\
\hline Bilobectomy & $4(14.8)$ \\
\hline Right-sided procedure & $17(63.0)$ \\
\hline Segments resected & $5(3,5)$ \\
\hline Duration of surgery (min) & $146.0(116.0,169.0)$ \\
\hline Duration of OLV (min) & $56.0(48.0,84.0)$ \\
\hline Intraoperative fluid administration $(\mathrm{mL})$ & $933.3(402.9)$ \\
\hline \multicolumn{2}{|l|}{ Pathology } \\
\hline Primary lung cancer & $24(88.9)$ \\
\hline Metastatic malignancy & $1(3.7)$ \\
\hline Benign & $2(7.4)$ \\
\hline \multicolumn{2}{|l|}{ Comorbidities* } \\
\hline History of cancer & 7 (25.9) \\
\hline COPD & $6(22.2)$ \\
\hline Hypertension & $9(33.3)$ \\
\hline Ischemic heart disease & $6(22.2)$ \\
\hline Diabetes mellitus & 0 \\
\hline Peripheral vascular disease & $5(18.5)$ \\
\hline Obesity & $2(7.4)$ \\
\hline Alcoholism & 0 \\
\hline Thoracic Surgery Scoring System (\%) & $0.7(0.5,0.8)$ \\
\hline Critical care unit length of stay (d) & $2.0(1.2,2.2)$ \\
\hline Hospital length of stay (d) & $8(7,11)$ \\
\hline $\begin{array}{l}\text { Values are presented as mean } \pm \text { standard deviatio } \\
\text { quartile 3). } \mathrm{SaO}_{2} \text {, Oxygen saturation; } F E V_{1} \text {, force } \\
F V C \text {, forced vital capacity; } T L C O \text {, transfer factor } \\
\text { lung ventilation; } C O P D \text {, chronic obstructive pulm } \\
\text { gery Scoring System definition of comorbidities. }\end{array}$ & $\begin{array}{l}\text { o), or median (quartile } 1 \text {, } \\
\text { atory volume in } 1 \text { second; } \\
\text { tbon monoxide; } O L V \text {, one } \\
\text { isease. *Per Thoracic Sur- }\end{array}$ \\
\hline
\end{tabular}

afterload - the RV input impedance-is a composite of both static and pulsatile components. ${ }^{16,17}$

Given the methodologic concerns regarding the techniques used to assess RV function in previous studies and ongoing uncertainty about the underlying mechanism, further work was required to understand the RV response to lung resection. Cardiovascular magnetic resonance (CMR) imaging is the noninvasive gold standard method for assessing RV structure and function. ${ }^{15,16}$ In addition to 
TABLE 2. Ventricular volumes and function over time

\begin{tabular}{|c|c|c|c|c|}
\hline Variable & Preoperative $(n=26)$ & Postoperative day $2(n=22)$ & 2 mo postoperative $(n=24)$ & $P$ value \\
\hline Heart rate (bpm) & $64.4 \pm 13.0$ & $77.0 \pm 11.0^{*}$ & $69.4 \pm 10.3 \dagger$ & $.002 \ddagger$ \\
\hline \multicolumn{5}{|c|}{ RV volume measurements } \\
\hline RVEF (\%) & $50.5 \pm 6.9$ & $45.6 \pm 4.5^{*}$ & $44.9 \pm 7.7^{*}$ & $.003 \ddagger$ \\
\hline RVEDV (mL) & $119.1 \pm 25.4$ & $125.9 \pm 22.5$ & $109.4 \pm 31.6$ & .019 \\
\hline RVESV (mL) & $59.8 \pm 17.1$ & $68.6 \pm 14.5^{*}$ & $59.8 \pm 17.6$ & $.040 \ddagger$ \\
\hline $\operatorname{RVSV}(\mathrm{mL})$ & $59.3 \pm 12.0$ & $57.3 \pm 10.7$ & $49.6 \pm 16.5^{*}$ & $.002 \ddagger$ \\
\hline RVSV/RVESV & $1.0(0.9,1.2)$ & $0.8(0.7,1.0) \S$ & $0.8(0.8,1.0) \S$ & $.011 \|$ \\
\hline \multicolumn{5}{|c|}{ LV volume measurements } \\
\hline $\operatorname{LVEF}(\%)$ & $58.4 \pm 7.1$ & $57.4 \pm 7.3$ & $59.7 \pm 9.3$ & $.621 \ddagger$ \\
\hline LVEDV (mL) & $109.2 \pm 19.5$ & $106.3 \pm 19.2$ & $93.6 \pm 28.2 *$ & $.001 \ddagger$ \\
\hline LVESV (mL) & $46.0 \pm 13.2$ & $46.0 \pm 14.2$ & $37.7 \pm 13.1$ & $.019 \ddagger$ \\
\hline LVSV (mL) & $63.2 \pm 11.7$ & $60.3 \pm 9.0$ & $55.9 \pm 18.0^{*}$ & $.004 \ddagger$ \\
\hline
\end{tabular}

Values are presented as mean \pm standard deviation or median (quartile 1, quartile 3). $R V$, Right ventricle; $R V E F$, right ventricular ejection fraction; $R V E D V$, right ventricular end diastolic volume; $R V E S V$, right ventricular end systolic volume; $R V S V$, right ventricular stroke volume; $L V$, left ventricle; $L V E F$, left ventricular ejection fraction; $L V E D V$, left ventricular end diastolic volume; $L V E S V$, left ventricular end systolic volume; $L V S V$, left ventricular stroke volume. *Significant difference from preoperative (paired $t$ test, $P<.05$ ). $†$ Significant difference from preoperative (Wilcoxon signed rank test, $P<.05$ ). $\ddagger$ One-way repeated measures analysis of variance. $\S$ Significant difference from postoperative day 2 (paired $t$ test, $P<.05$ ). $\|$ Friedman test.

accurate quantification of volumes, CMR imaging allows PA flow quantification ${ }^{15,22}$ so that pulsatile components of afterload can be explored. ${ }^{23}$

Although RVEF is a commonly used index of function, it is highly load dependent and does not fully reflect RV contractility. ${ }^{16}$ Changes in RVEF can therefore result from alterations in the loading conditions, contractility, or a combination. A more comprehensive assessment of RV and pulmonary vascular function can be provided by considering the matching between contractility and afterload. Maximal ventricular elastance is a load-independent parameter used to characterize RV contractility. Arterial elastance is an index of afterload faced by the ventricle. The ratio of these 2 elastances reflects RV-PA coupling (coupling) and reflects matching between the ventricle and pulmonary circulation. An estimate of coupling can be obtained noninvasively with CMR imaging, using a ratio of volume measurements (stroke volume to end systolic volume [SV:ESV]). ${ }^{24}$

The aim of this CMR imaging study was to provide a comprehensive understanding of changes in the RV/pulmonary vascular unit following lung resection. ${ }^{24}$ Plasma biomarkers of myocardial dysfunction were measured contemporaneously.

\section{METHODS \\ Subjects}

Ethics approval was provided by the West of Scotland Research Ethics Committee (134/WS/0055) and all participants provided written informed consent. Patients presenting for elective lung resection by thoracotomy and lobectomy were screened. Subjects who were pregnant; participating in any investigational research that could undermine the scientific basis of the study; had contraindications to CMR imaging; or were undergoing wedge/segmental/sublobar lung resection, pneumonectomy, isolated middle lobectomy, or thoracoscopic/minimal access lung resection were excluded. Surgical technique was standardized to a single surgeon performing a posterolateral muscle sparing thoracotomy with anatomically appropriate lymph node clearance. Anesthetic technique was standardized and included volatile agents for anesthetic maintenance, intraoperative lung protective ventilatory strategies, and thoracic epidural blockade.

\section{Measurements}

CMR imaging (1.5 Tesla Siemens Avanto; Siemens, Erlangen, Germany) was performed within 24 hours preoperatively, on postoperative day (POD) 2 and at 2 months. Electrocardiogram-gated fast imaging steady-state free precession cines (TrueFISP; Siemens) were utilized throughout. Methodologic details of importance include standardized imaging parameters of repetition time; echo time; flip angle; voxel size; field of view $=4.3 \mathrm{~ms}, 1.2 \mathrm{~ms}, 60^{\circ}, 1.4 \times 1.4 \times 6 \mathrm{~mm}, 340 \mathrm{~mm}$, respectively; and 6-mm imaging slices were used with a $4 \mathrm{~mm}$ interslice gap. Short axis imaging was performed during breath holds and initiated at the atrioventricular valve plane and propagated sequentially to the cardiac apex providing complete coverage of both ventricles. Analysis of randomized and anonymized images was performed by 2 independent reporters using proprietary software (Argus; Siemens). RV and left ventricular (LV) volumes were determined by manual planimetry of short-axis images according to standard methods. ${ }^{25}$ The ratio of RV SV:ESV was derived as an index of right ventriculoarterial coupling. ${ }^{24}$

Flow imaging was performed with velocity-encoded gradient sequencing of the main PA and of both left and right PAs. Mapping was set for the main PA perpendicular to the vessel and above the valve level with velocity encoding at $150 \mathrm{~cm} / \mathrm{second}$. Mapping for the branch PAs was perpendicular to the vessel, proximal to first dividing vessel with velocity encoding at $150 \mathrm{~cm} / \mathrm{second}$. Main and branch PA contours were delineated by manual planimetry. Cubic splines with interpolation to $1 \mathrm{~ms}$ temporal resolution were then fitted to flow and area versus time curves allowing calculation of PA acceleration time (PAAT) and distensibility for the main and branch PAs. ${ }^{26}$ PAAT is the time to peak flow (in milliseconds) from the onset of the cardiac cycle, distensibility (\%) was calculated as $100 \times($ maximum-minimum PA area)/minimum PA area.

Biomarkers of myocardial function were based on blood samples collected preoperatively, immediately postoperatively, on the morning of POD1 and POD2, and at 2 months. B-type natriuretic peptide (BNP) was analyzed immediately using the Alere Triage System (Alere, Stockport, United Kingdom). High-sensitivity troponin $\mathrm{T}$ (hsTnT) was analyzed 

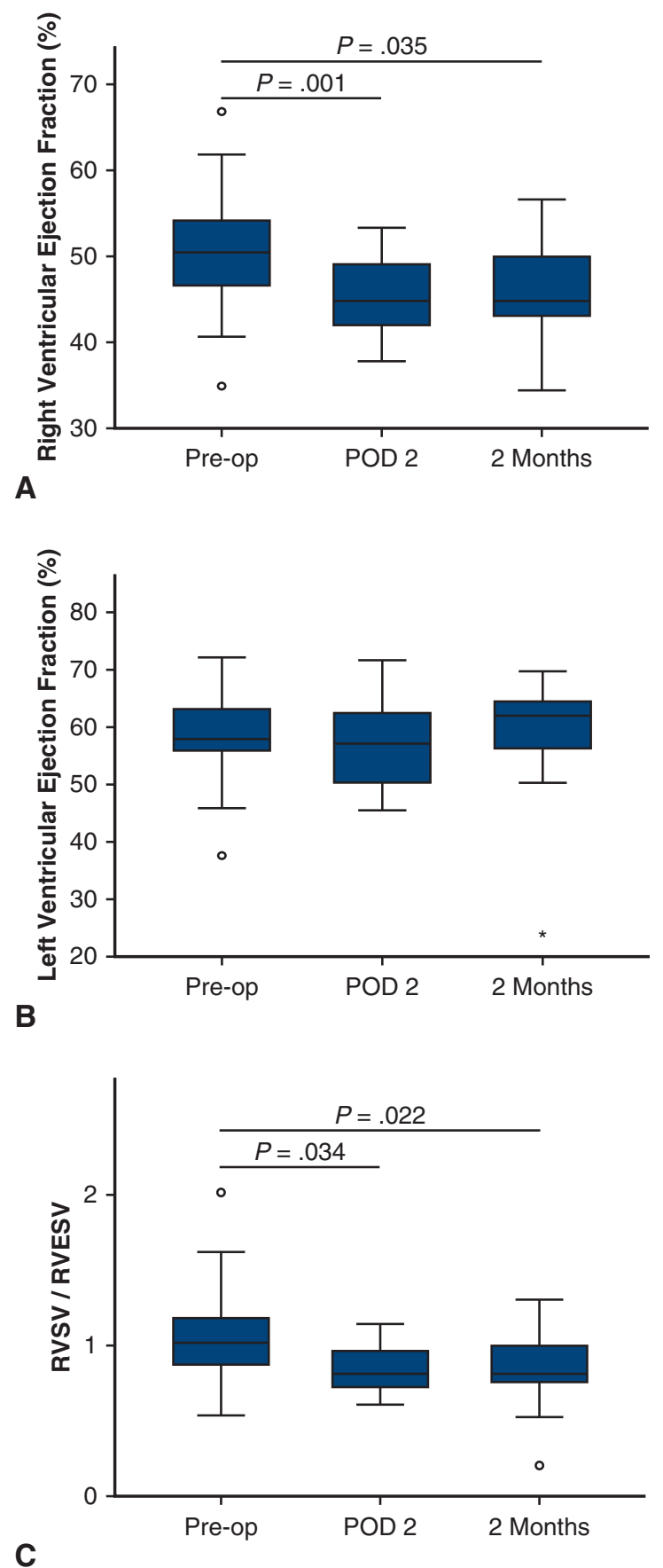

FIGURE 1. Ventricular ejection fraction and coupling over time. For box plots, the middle horizontal line represents the median, the boxes represent the interquartile range (IQR), and the whiskers represent the range of values no greater than 1.5 times the IQR. Circles represent outliers and are values 1.5 to 3 times IQR. A, Decrease in right ventricular ejection fraction (RVEF) on postoperative day $(P O D) 2$, remaining reduced at 2 months. $\mathrm{B}$, No changes in left ventricular ejection fraction (LVEF) over time. C, Deterioration in the stroke volume/end systolic volume ratio (SV/ESV) over the study period. RVSV, Right ventricular stroke volume; RVESV, right ventricular end systolic volume. immediately using a Roche-Cobas 6000e analyzer (Roche, Basel, Switzerland).

\section{Statistical Methods}

Power analysis was carried out in consultation with the Robertson Centre for Biostatistics at the University of Glasgow. Primary outcome was change in RVEF on POD2. Although the validity of previous work has been questioned, these studies suggested an absolute fall in RVEF of a range of $6 \%$ to $9 \%$ by $\mathrm{POD} 29,10$ and our study was powered to detect a change of at least this magnitude. They also suggest that mean RVEF is $45 \%$ and that the largest standard deviation is assumed to be $7 \%$. Power analysis was based on a 2-sided, paired $t$ test and indicated that 19 patients would have $80 \%$ power to detect an absolute reduction in RVEF of $6 \%$, with a significance level of .05 . Allowing a margin of $30 \%$ for study withdrawal, 28 patients were recruited.

Data are presented as mean \pm standard deviation or median (quartile 1, quartile 3) as appropriate. Changes over time were assessed using 1-way repeated measures analysis of variance or Friedman test with post hoc pairwise comparisons using paired $t$ test or Wilcoxon signed rank test. Comparisons between independent groups were performed using the independent $t$ test or Mann-Whitney $U$ test. Association between continuous variables was assessed using Pearson or Spearman correlation coefficients. Bonferroni corrected $P$ values are presented throughout.

Statistical analyses were performed using SPSS for Windows, version 22 (IBM-SPSS Inc, Armonk, NY).

\section{RESULTS}

Twenty-eight patients were recruited. One patient was excluded due to the unexpected discovery of an embedded piece of ferromagnetic material in the chest wall during preoperative scanning, meaning no usable images could be obtained. There were no clinical sequelae, but because this patient was unable to take any part in the main study, the patient was removed from all further analyses. Patient demographic characteristics are displayed in Table 1. Twenty-six patients underwent lobectomy or bilobectomy (incorporating the right middle lobe) and 1 patient required unplanned intraoperative conversion to a pneumonectomy and is included in all analyses. Sensitivity analysis revealed this patient was not an outlier in any analysis (not shown).

CMR imaging was well tolerated, with all patients completing the scan protocol preoperatively. Due to an administration error, 1 participant did not have short axis images obtained, meaning it was not possible to calculate ventricular volumes in this patient. Twenty-two patients $(81.5 \%)$ completed the protocol on POD2 and 24 patients $(88.9 \%)$ completed the protocol at 2 months. Time to final follow-up was $55.9 \pm 13.1$ days. Of 5 patients unable to undergo imaging on POD2, 3 declined, 1 was unwell with persistent air-leak requiring additional intercostal catheter drainage with CMR imaging transfer deemed unsafe, and 1 patient had an epidural catheter in situ that was not CMR imaging compatible. Of patients unable to complete the protocol at 2 months, 1 declined, 1 was an inpatient at another hospital, and the third had a contraindication to 
TABLE 3. Pulmonary artery acceleration time (PAAT) and distensibility index

\begin{tabular}{|c|c|c|c|c|}
\hline Variable & Preoperative $(n=26)$ & Postoperative day $2(n=22)$ & 2 mo postoperative $(n=24)$ & $P$ value \\
\hline \multicolumn{5}{|l|}{ PA flow (L/min) } \\
\hline Main PA flow & $6.6 \pm 1.7$ & $8.0 \pm 1.6^{*}$ & $6.5 \pm 1.7 \dagger$ & $.004 \ddagger$ \\
\hline Operative PA flow & $3.0 \pm 0.8$ & $2.3 \pm 0.7^{*}$ & $2.3 \pm 0.8^{*}$ & $.004 \ddagger$ \\
\hline Nonoperative PA flow & $2.8 \pm 1.0$ & $4.7 \pm 1.4^{*}, \S$ & $3.8 \pm 1.5^{*}, \dagger, \S$ & $<.001 \ddagger$ \\
\hline \multicolumn{5}{|l|}{ PAAT (ms) } \\
\hline Main PA & $115.9 \pm 20.7$ & $82.7 \pm 18.9^{*}$ & $104.0 \pm 19.5 \dagger$ & $<.001 \ddagger$ \\
\hline Operative PA & $124.7 \pm 19.3$ & $82.1 \pm 23.0^{*}$ & $106.0 \pm 23.9^{*}, \dagger$ & $<.001 \ddagger$ \\
\hline Nonoperative PA & $128.0 \pm 24.8$ & $100.5 \pm 18.8^{*}, \S$ & $121.4 \pm 20.4 \uparrow, \S$ & $<.001 \ddagger$ \\
\hline \multicolumn{5}{|l|}{ Distensibility (\%) } \\
\hline Main PA & $32.0(26.9,46.0)$ & $29.8(22.3,38.8)$ & $28.4(25.8,39.6)$ & $.818 \|$ \\
\hline Operative PA & $65.2 \pm 25.5$ & $50.7 \pm 16.9$ & $51.8 \pm 16.2$ & $.027 \ddagger$ \\
\hline Nonoperative PA & $62.6 \pm 23.2$ & $54.4 \pm 17.7$ & $69.2 \pm 28.0^{\dagger}, \S$ & $.120 \ddagger$ \\
\hline
\end{tabular}

Values are presented as mean \pm standard deviation or median (quartile 1, quartile 3). PA, Pulmonary artery; PAAT, pulmonary artery acceleration time. *Significant difference from preoperative (paired $t$ test, $P<.05$ ). $\dagger$ Significant difference from postoperative day 2 (paired $t$ test, $P<.05$ ). †One-way repeated measures analysis of variance. $\S$ Significant difference from operative vessel at given point in time (independent samples $t$ test, $P<.05$ ). $\|$ Friedman test.

CMR imaging as a result of recent cataract surgery. The baseline characteristics of those completing and not completing follow-up are described in Table E1.

\section{CMR Ventricular Volumetric and Flow Velocity Mapping}

Coefficient of variation for RVEF was $12.9 \%$ preoperatively, $16.8 \%$ on POD2, and $15.9 \%$ at 2 months. Mean \pm standard deviation RVEF fell from $50.5 \% \pm 6.9 \%$ preoperatively to $45.6 \% \pm 4.5 \%$ on POD2 and remained reduced at $44.9 \% \pm 7.7 \%$ at 2 months $(P=.003)$ (Table 2 and Figure $1, A)$. There were no changes in LV ejection fraction over the study period $(P=.621)$ (Figure $1, B$ ). There was a deterioration in RV SV:ESV on POD2, which persisted at 2 months $(P=.011)$ (Table 2 and Figure 1,C).

RVESV increased on POD2, returning to baseline levels at 2 months. LV end diastolic volume, ESV, and SV were unchanged on POD2. All other LV and RV volumes were reduced at 2 months (Table 2).

Main PA flow increased from $6.6 \pm 1.7 \mathrm{~L} / \mathrm{min}$ to $8.00 \pm 1.6 \mathrm{~L} / \mathrm{min}$ on POD2, returning to baseline $(6.52 \pm 1.7 \mathrm{~L} / \mathrm{min})$ by 2 months $(P=.004)$ (Table 3 and Figure $2, A)$. This increase in cardiac output $(\mathrm{CO})$ resulted from increased heart rate (Table 2). Preoperatively, there was an even distribution of $\mathrm{CO}$ between the left and right PAs $(48.1 \%$ and $51.9 \% ; P=.055)$. This distribution was altered postoperatively with $66.3 \%$ and $60.9 \%$ of the $\mathrm{CO}$ traveling through the nonoperative vessel on POD2 and at 2 months, respectively $(P<.001)$ (Table 3 and Figure 2, $B$ ).

POD2 PAAT was reduced in all vessels with PAAT shorter in the operative versus nonoperative vessel. At 2 months, PAAT remained shorter than preoperative values in the main PA and operative vessel. At 2 months, operative
PAAT was again shorter than nonoperative PAAT (Table 3 and Figure 3, $A$ and $B$ ).

Main PA distensibility was unchanged throughout the study. Nonoperative PA distensibility increased in comparison to POD2 at 2 months, and was higher than the operative vessel at this time point (Table 3 and Figure 3,C). There were no consistent associations between PAAT, distensibility, and RVEF at any time (Table E2 and Table E3).

There is a moderate positive association between the transfer factor for carbon monoxide (TLCO) and the change in RVEF from preoperative to POD2 $\left(\triangle \mathrm{RVEF}_{\mathrm{POD} 2 \text {-pre }}\right.$, Pearson $r=0.517, P=.014$ ) (Figure E1). There was no association between any of the operative variables described in Table 1 and any the CMR variables (RVEF, PAAT, and distensibility). There was a strong negative association between RVEF on POD2 and the duration of critical care unit stay (Spearman $r=-0.653 ; P=.001$ ) (Figure E2). There was no association between RVEF at any time point and duration of hospital stay.

\section{Biomarkers of Myocardial Function}

Coefficients of variation for BNP and hsTnT were 5.9\% and $<10 \%$, respectively. BNP increased over time, peaking on POD2 and returning to baseline by 2 months (Table 4 and Figure 4, A). HsTnT showed a small but significant postoperative rise (Table 4 and Figure 4, $B$ ). There was moderate association between $\triangle \mathrm{RVEF}_{\mathrm{POD} 2-\text { pre }}$ and BNP on POD2 (Pearson $r=-0.490 ; P=.021$ ) (Figure $4, C$ ). There was no association between troponin and RVEF on POD2 (Figure 4,D). Associations at other time points are detailed in Table E4.

\section{DISCUSSION}

The main finding of this study (the first using CMR to describe changes in RV function following lung resection) is that $\mathrm{RV}$ function deteriorated by POD2 and remained 


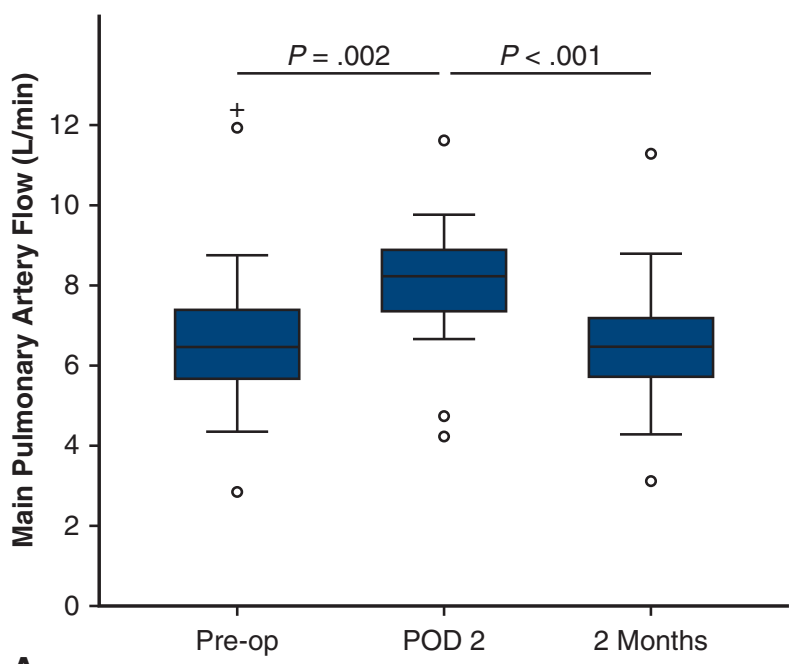

A

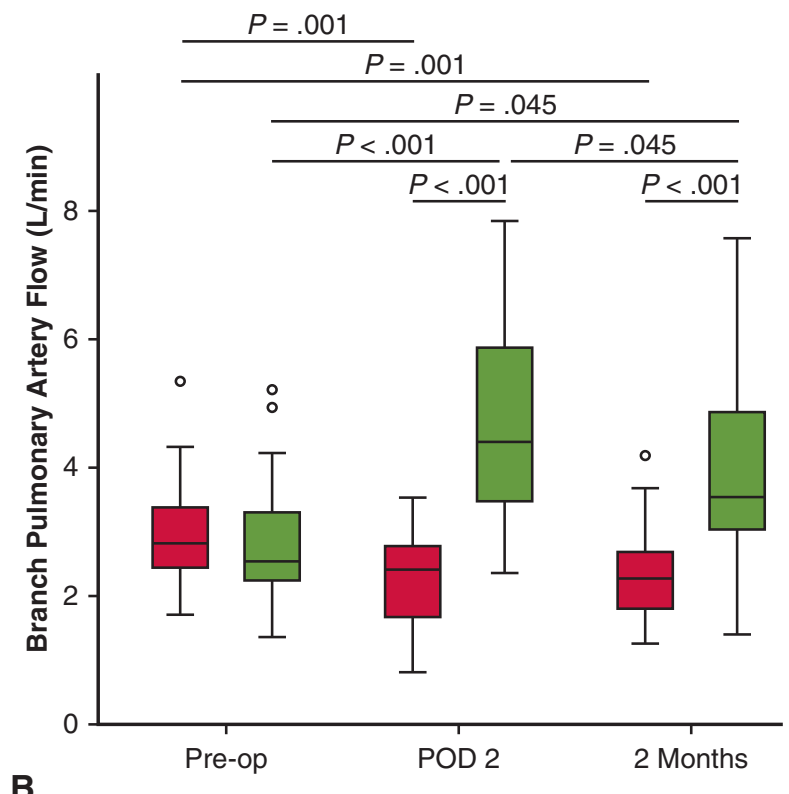

FIGURE 2. Pulmonary artery flow over time. For box plots, the middle horizontal line represents the median, the boxes represent the interquartile range (IQR), and the whiskers represent the range of values no greater than 1.5 times the IQR. Circles represent outliers and are values 1.5 to 3 times IQR. Blue bars represent the main pulmonary artery (MPA), red bars represent the operative pulmonary artery (OPA), and green bars represent the nonoperative pulmonary artery (NPA). A, Flow in the MPA increases on postoperative day $(P O D) 2$ before returning to preoperative levels by 2 months. B, Postoperative distribution of cardiac output between the 2 pulmonary arteries is altered, with reduced flow through the OPA on POD2 and at 2 months.

depressed at 2 months. This is shown by a median relative decrease in RVEF of $10.9 \%$ from baseline on POD2, with 4 patients experiencing a relative decrease of RVEF in excess of $20.0 \%$. The observed changes in RV function occurred despite preservation of LV function, meaning changes following lung resection primarily influence the $\mathrm{RV} /$ pulmonary vascular unit. The association between pulmonary function and deterioration in RVEF by POD2 suggests those patients with poorer lung function are also likely to be those with a larger deterioration in RV function, meaning this group may be at particular risk.

CMR imaging was feasible and well tolerated postoperatively with more than $80 \%$ of patients completing the examination protocol. RVEF assessment was reproducible with coefficients of variation (CV) between $12.9 \%$ and $16.8 \%$. This is the first study to describe CMR in a lung resection cohort-CVs in this population have not previously been described. Work in normal subjects and those with cardiac pathology have shown CVs for RVEF between $8.0 \%$ and $10.7 \% .{ }^{27}$ Our study had higher CVs; however, post hoc analyses suggest surgical side was important to observed variability. Preoperative CVs were similar for those having left- or right-sided resections $(12.75 \%$ and $13.21 \%$, respectively). Postoperatively, those patients with right-sided resections had larger CVs $(20.48 \%$ on POD2 and $16.92 \%$ at 2 months) than those having left-sided surgery $(11.53 \%$ and $13.81 \%$, respectively). Future studies using CMR imaging in this population for mechanistic research may wish to prioritize patients undergoing left-sided resections.

As described in the introduction, a more complete assessment of RV and pulmonary vascular function can be provided by measuring the matching between contractility and afterload. The CMR imaging surrogate approximation used in this study has compared favorably to a combined PA catheter and CMR imaging determined coupling measurement in a cohort with pulmonary hypertension. ${ }^{24}$ This ratio incorporates a number of assumptions, firstly that ventricular volume at time zero is negligible, and secondly it calculates end systolic elastance and not maximal elastance. $^{28-30}$ Our patients show SV:ESV 1.0 that falls following surgery suggesting a deterioration in the matching of contractility and afterload that is still present 2 months following surgery.

Although widely hypothesized, increased afterload following lung resection has not been demonstrated. ${ }^{10,18,21}$ PAAT and PA distensibility are indices of afterload that do not assume constant flow (as PVR assumes), providing some insight into the pulsatile nature of afterload. Reduced PAAT has been associated with abnormal wave reflections (increased pulsatile afterload) in pulmonary hypertension. ${ }^{26}$ Reduced PA distensibility suggests decreased compliance of the pulmonary vessels, increasing afterload. ${ }^{31,32}$

We observed a decrease in PAAT in all vessels on POD2, with the greatest decrease in the operative vessel. At 2 months, main PAAT remains reduced, and although nonoperative PAAT returns to preoperative levels, operative PAAT remains lower. These findings suggest that postoperatively there is increased afterload in the operative vessel, potentially due to increased wave reflection. 


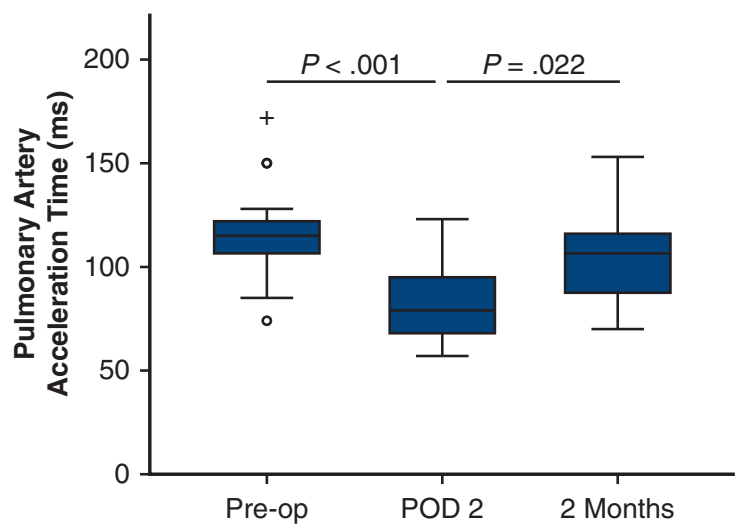

A

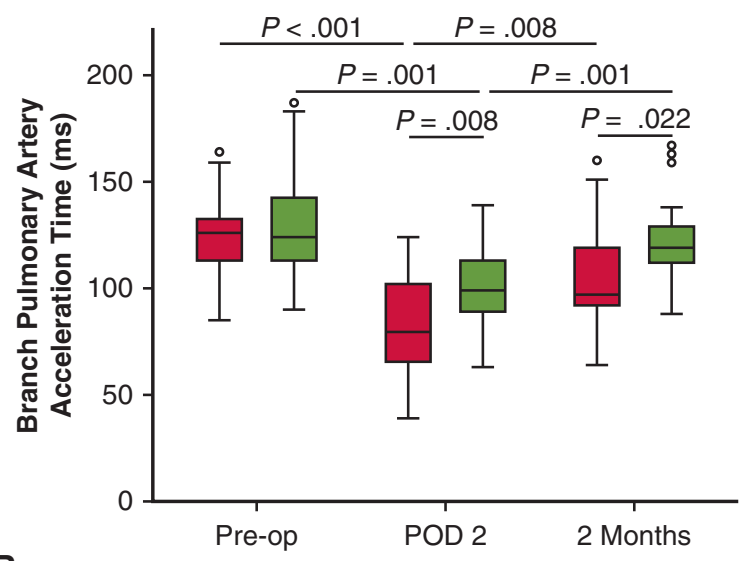

B

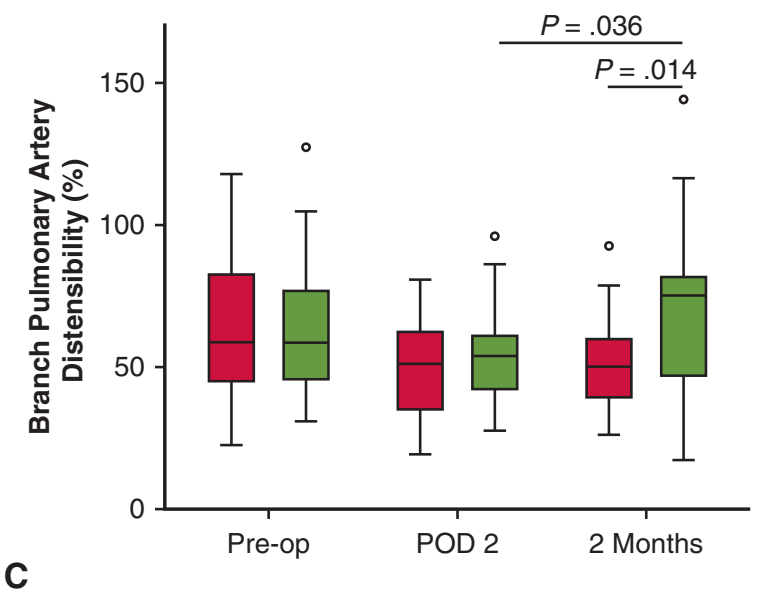

FIGURE 3. Pulmonary artery acceleration time (PAAT) and distensibility over time. For box plots, the middle horizontal line represents the median, the boxes represent the interquartile range (IQR), and the whiskers represent the range of values no greater than 1.5 times the IQR. Circles and positive symbols $(+)$ represent outliers and are values 1.5 to 3 and $>3$ times IQR, respectively. Blue bars represent the main pulmonary artery (MPA), green bars represent the operative pulmonary artery (OPA), and green bars represent the nonoperative pulmonary artery (NPA). A, PAAT in the MPA is reduced postoperatively, remaining reduced from preoperative levels at 2 months. B, PAAT in the OPA is reduced on postoperative day
There were no changes in main PA distensibility; however, determination of distensibility in this vessel can be complicated by cardiac movement distorting the cross-sectional plane, compromising the measurement. ${ }^{33}$ This was our experience, with diastolic increases in cross-sectional area not reflected in either changes in flow in the main PA, or area of the branch pulmonary vessels. Operative distensibility was lower than preoperative distensibility at 2 months, again suggesting increased afterload on this side.

The changes in PAAT and distensibility, in addition to reduced operative PA blood flow, suggest changes in afterload mainly result from the operative PA. PAAT and distensibility are surrogate indices of pulsatile afterload but only partially reflect changes in overall PA impedance. This may account for the lack of observed association between either of these measures and RVEF. In-depth analysis of pulsatile afterload is required to further explore any association between changes in afterload and RV function following lung resection. Additionally, it must be recognized that the observed changes in RVEF could also occur as a result of intrinsic changes in RV contractility that could not be fully accounted for in this study.

BNP and hsTnT are quantitative biomarkers of myocardial injury. BNP is released in response to myocardial stretch and has been measured in patients undergoing lung resection, with elevated perioperative levels associated with early postoperative cardiopulmonary complications. ${ }^{34}$ We observed association between POD2 BNP and both $\mathrm{RVEF}_{\mathrm{POD} 2}$ and change in $\mathrm{RVEF}_{\mathrm{POD} 2-\mathrm{pre}}$. We found no association between LVEF and BNP (not shown), suggesting $\mathrm{BNP}$ is released in response to changes within the RV. We found no association with change in RV function and troponin at any time point.

\section{Clinical Implications}

This is the first study showing that RV function is impaired not just during the immediate perioperative period following lung resection, but months later, long into the recovery period. In other clinical settings, such as heart failure and pulmonary hypertension, $\mathrm{RV}$ dysfunction is associated with poor prognosis and reduced exercise capacity. We hypothesize that reduced RVEF following lung resection is likely to have clinical sequelae such as dyspnea and reduced functional capacity. The RV and pulmonary vasculature may provide a target for future perioperative interventions, allowing amelioration of long-term cardiorespiratory morbidity.

$(P O D) 2$ and despite partial recovery, remains reduced at 2 months. PAAT in the NPA is reduced on POD2 but recovers by 2 months. PAAT is lower in the OPA on POD2 and at 2 months. C, Distensibility in the OPA is reduced on POD2 and at 2 months. Distensibility in the OPA is lower than the NPA at 2 months. 
TABLE 4. Biomarkers of myocardial function

\begin{tabular}{|c|c|c|c|c|c|c|}
\hline Biomarker & $\begin{array}{c}\text { Immediate } \\
\text { preoperative } \mathbf{n}=\mathbf{2 7}\end{array}$ & $\begin{array}{c}\text { Immediate } \\
\text { postoperative } n=27\end{array}$ & $\begin{array}{l}\text { Postoperative } \\
\text { day } 1 \mathbf{n}=27\end{array}$ & $\begin{array}{l}\text { Postoperative } \\
\text { day } 2 \mathbf{n}=27\end{array}$ & $\begin{array}{c}2 \text { mo postoperative } \\
n=24\end{array}$ & $P$ value \\
\hline \multirow[t]{2}{*}{$\begin{array}{l}\text { B-type natriuretic } \\
\text { peptide }(\mathrm{pg} / \mathrm{mL})\end{array}$} & $28.0(5.0,160.0)$ & $32.0(6.0,170)$ & $71.0(5.0,381.0)^{*}$ & $93.0(5.0,304.0)^{*}$ & $28.5(5.0,199.0) \dagger, \ddagger$ & $<.001 \S$ \\
\hline & $\mathbf{n}=\mathbf{2 6}$ & $\mathbf{n}=\mathbf{2 6}$ & $\mathbf{n}=\mathbf{2 6}$ & $\mathbf{n}=\mathbf{2 6}$ & $\mathbf{n}=\mathbf{2 2}$ & \\
\hline $\begin{array}{l}\text { High-sensitivity } \\
\text { troponin } \mathrm{T}(\mathrm{pg} / \mathrm{mL})\end{array}$ & $6.8(3.0,27.2)$ & $6.9(3.0,23.2)$ & $12.3(3.7,21.9)^{*}, \|$ & $9.5(3,20.7) \|$ & $9.0(3.9,24.9) \|$ & $<.001 \S$ \\
\hline
\end{tabular}

Values are presented as median (quartile 1, quartile 3 ). $*$ Significant difference from preoperative (Wilcoxon signed rank test, $P<.05$ ). $\dagger$ Significant difference from postoperative day 1 (Wilcoxon signed rank test, $P<.05$ ). ఫSignificant difference from postoperative day 2 (Wilcoxon signed rank test, $P<.05$ ). $§$ Friedman test. $\|$ Significant difference from immediate postoperative (Wilcoxon signed rank test, $P<.05$ ).

\section{Limitations}

Although there is association between duration of critical care admission and postoperative RV function, this does not suggest that it is causative. The reasons for remaining in critical care are multifactorial and some of the complications that may prolong stay could in themselves cause RV

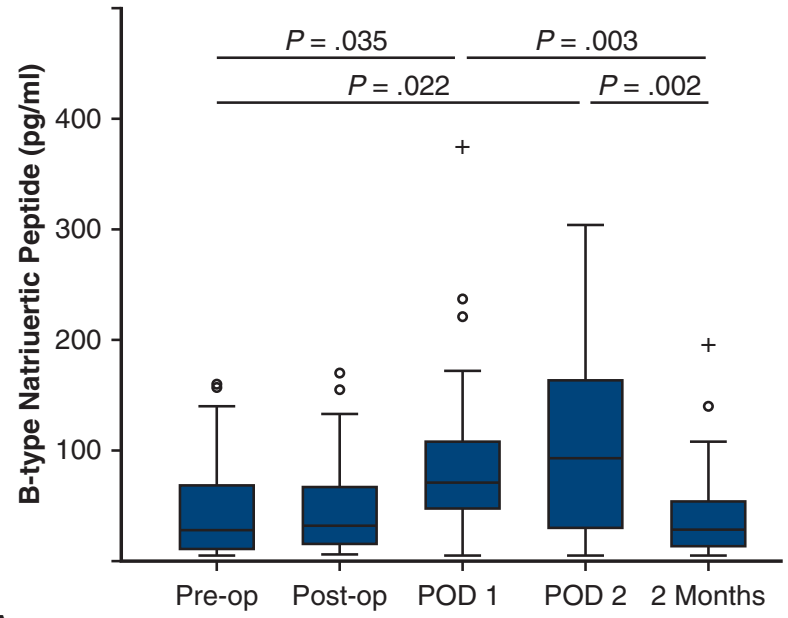

A

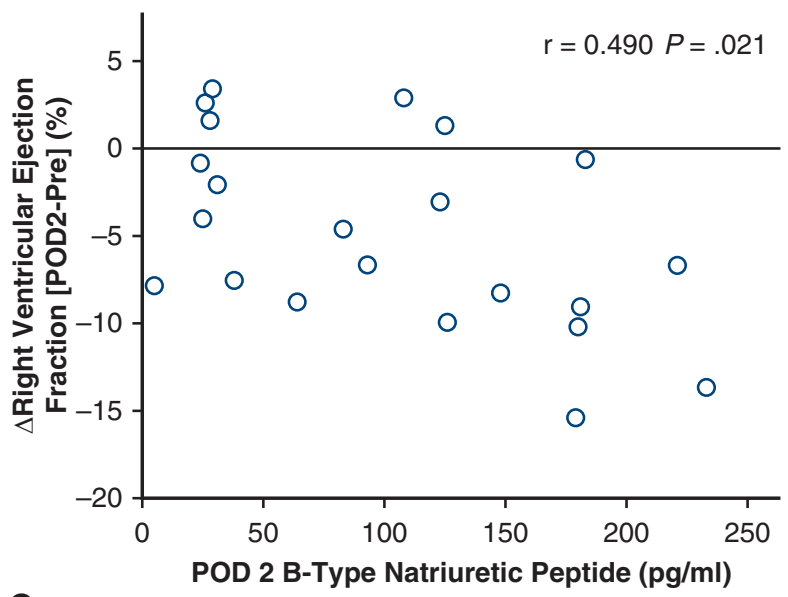

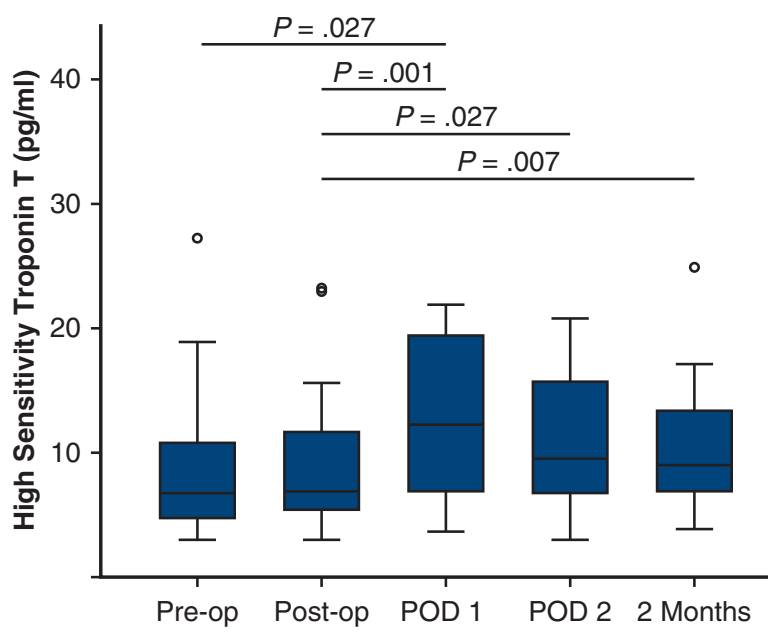

B

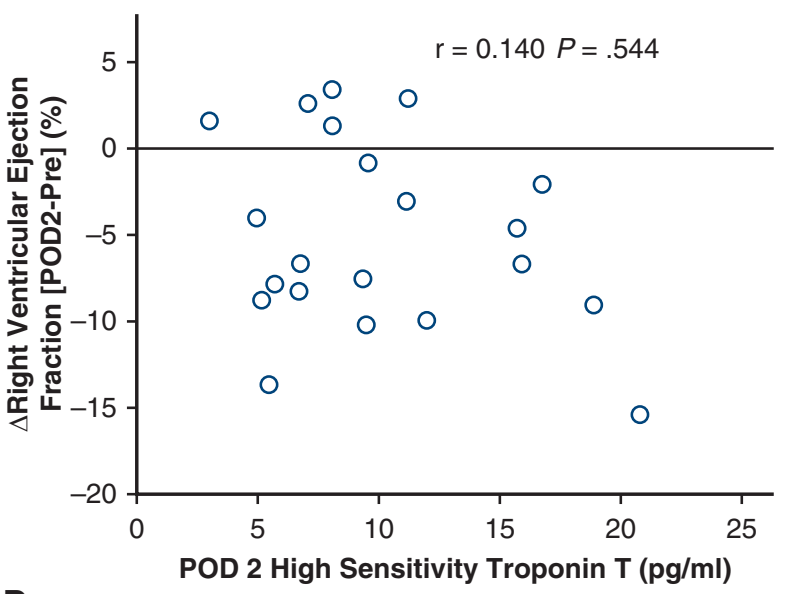

FIGURE 4. Biomarkers of myocardial function. For box plots, the middle horizontal line represents the median, the boxes represent the interquartile range (IQR), and the whiskers represent the range of values no greater than 1.5 times the IQR. Circles and positive symbols $(+)$ represent outliers and are values 1.5 to -3 and $>3$ times IQR, respectively. A, Changes in B-type natriuretic peptide over time, peaking on postoperative day (POD) 2 . B, Changes in highsensitivity troponin T (hsTnT) over time, peaking on POD1. C, Moderate association of change in right ventricular ejection fraction from preoperative to POD2 ( $\triangle \mathrm{RVEF}[\mathrm{POD} 2-\mathrm{Pre}])$ and B-type natriuretic peptide on POD2. D, No association between $\triangle \mathrm{RVEF}$ [POD2 - Pre] and hsTnT on POD2. $P O D$, Postoperative day. 
dysfunction. This was a proof-of-concept study and its size means any clinical associations can only be hypothesisgenerating and do not allow robust clinical correlation; future work should fully assess the clinical implications of RV dysfunction.

We made no assessment of RV function during exercise, previous work in this patient group has consistently shown marked changes in pulmonary hemodynamics and RV function on exercise. ${ }^{18,35}$ Although the deterioration in RVEF observed is modest, we suggest the changes observed at rest would be exacerbated during exercise.

CMR imaging is a reference method for assessing RV volumes, but its use in this group is limited, first by availability and second by suitability in immediatepostoperative patients. Although withdrawals were well within the number allowed by the study's power analysis, a group of participants was unable to undergo CMR imaging assessment postoperatively. A validated bedside alternative to CMR imaging for the assessment of RV structure and function, potentially utilizing transthoracic echocardiography, biomarkers, or a combination, would have utility in this population.

\section{CONCLUSIONS}

RV function is impaired immediately postoperatively following lung resection and this persists at 2 months. There is a deterioration in SV:ESV with evidence of increased afterload. There was moderate association between postoperative RV function and BNP. Future work should focus on assessing the mechanisms and clinical implications of postoperative RV dysfunction and on assessment of RV function during exercise.

\section{Conflict of Interest Statement}

Dr Johnson has received grants from Actelion, Bayer, and GlaxoSmithKline outside the submitted work. All other authors have nothing to disclose with regard to commercial support.

The authors thank Vanessa Orchard (lead cardiovascular magnetic resonance imaging radiographer) and Des Alcorn (consultant radiologist) for assisting with the cardiovascular magnetic resonance imaging component of the study.

\section{References}

1. Licker M, de Perrot M, Hohn L, Tschopp JM, Robert J, Frey JG, et al. Perioperative mortality and major cardio-pulmonary complications after lung surgery for non-small cell carcinoma. Eur J Cardiothorac Surg. 1999;15:314-9.

2. McCall PJ, Macfie A, Kinsella J, Shelley BG. Critical care after lung resection: CALoR 1, a single-centre pilot study. Anaesthesia. 2015;70:1382-9.

3. Sarna L, Evangelista L, Tashkin D, Padilla G, Holmes C, Brecht ML, et al. Impact of respiratory symptoms and pulmonary function on quality of life of long-term survivors of non-small cell lung cancer. Chest. 2004;125:439-45.

4. Larsen KR, Svendsen UG, Milman N, Brenoe J, Petersen BN. Cardiopulmonary function at rest and during exercise after resection for bronchial carcinoma. Ann Thorac Surg. 1997;64:960-4.
5. Pelletier C, Lapointe L, Leblanc P. Effects of lung resection on pulmonaryfunction and exercise capacity. Thorax. 1990;45:497-502.

6. Brunelli A, Xiume F, Refai M, Salati M, Marasco R, Sciarra V, et al. Evaluation of expiratory volume, diffusion capacity, and exercise tolerance following major lung resection. A prospective follow-up analysis. Chest. 2007;131:141-7.

7. Nugent AM, Steele IC, Carragher AM, McManus K, McGuigan JA, Gibbons JRP, et al. Effect of thoracotomy and lung resection on exercise capacity in patients with lung cancer. Thorax. 1999;54:334-8.

8. Vainshelboim B, Fox BD, Saute M, Sagie A, Yehoshua L, Fuks L, et al. Limitations in exercise and functional capacity in long-term postpneumonectomy patients. J Cardiopulm Rehabil Prev. 2015;35:56-64.

9. Reed CE, Dorman H, Spinale FG. Mechanisms of right ventricular dysfunction after pulmonary resection. Ann Thorac Surg. 1996;62:225-32.

10. Bäcklund M, Laasonen L, Lepäntalo M, Metsärinne K, Tikkanen I, Lindgren L. Effect of oxygen on pulmonary hemodynamics and incidence of atrial fibrillation after noncardiac thoracotomy. J Cardiothorac Vasc Anesth. 1998;12: 422-8.

11. Lewis JW, Bastanfar M, Gabriel F, Mascha E. Right heart function and prediction of respiratory morbidity in patients undergoing pneumonectomy with moderately severe cardiopulmonary dysfunction. J Thorac Cardiovasc Surg. 1994;108: 169-75.

12. Matyal R, Mahmood F, Hess P, Zhao X, Mitchell J, Maslow A, et al. Right ventricular echocardiographic predictors of postoperative supraventricular arrhythmias after thoracic surgery: a pilot study. Ann Thorac Surg. 2010;90: 1080-7.

13. Amar D, Roistacher N, Burt M, Reinsel RA, Ginsberg RJ, Wilson RS. Clinical and echocardiographic correlates of symptomatic tachydysrhythmias after noncardiac thoracic-surgery. Chest. 1995;108:349-54.

14. Kowalewski J, Brocki M, Dryjanski T, Kapron K, Barcikowski S. Right ventricular morphology and function after pulmonary resection. Eur J Cardiothorac Surg. 1999;15:444-8.

15. McLure LER, Peacock AJ. Cardiac magnetic resonance imaging for the assessment of the heart and pulmonary circulation in pulmonary hypertension. Eur Respir J. 2009:33:1454-66.

16. Haddad F, Hunt SA, Rosenthal DN, Murphy D. Right ventricular function in cardiovascular disease, part 1. Anatomy, physiology, aging, and functional assessment of the right ventricle. Circulation. 2008;117:1436-48.

17. Champion HC, Michelakis ED, Hassoun PM. Comprehensive invasive and noninvasive approach to the right ventricle-pulmonary circulation unit: state of the art and clinical and research implications. Circulation. 2009;120: 992-1007.

18. Okada M, Ota T, Okada M, Matsuda H, Okada K, Ishii N. Right ventricular dysfunction after major pulmonary resection. J Thorac Cardiovasc Surg. 1994; 108:503-11.

19. Leibowitz A. Pulmonary artery catheter determined right ventricular ejection fraction and right ventricular end-diastolic volume: another case of "the emperor has no clothes". Crit Care Med. 2009;37:2992.

20. Hein M, Roehl AB, Baumert JH, Rossaint R, Steendijk P. Continuous right ventricular volumetry by fast-response thermodilution during right ventricular ischemia: head-to-head comparison with conductance catheter measurements. Crit Care Med. 2009;37:2962-7.

21. Reed CE, Spinale FG, Crawford FA Jr. Effect of pulmonary resection on right ventricular function. Ann Thorac Surg. 1992;53:578-82.

22. Ibrahim el SH, White RD. Cardiovascular magnetic resonance for the assessment of pulmonary arterial hypertension: toward a comprehensive CMR exam. Magn Res Imaging. 2012;30:1047-58.

23. Furuno Y, Nagamoto Y, Fujita M, Kaku T, Sakurai S, Kuroiwa A. Reflection as a cause of mid-systolic deceleration of pulmonary flow wave in dogs with acute pulmonary hypertension: comparison of pulmonary artery constriction with pulmonary embolisation. Cardiovasc Res. 1991;25:118-24.

24. Sanz J, García-Alvarez A, Fernández-Friera L, Nair A, Mirelis JG, Sawit ST, et al. Right ventriculo-arterial coupling in pulmonary hypertension: a magnetic resonance study. Heart. 2012;98:238-43.

25. Schulz-Menger J, Bluemke DA, Bremerich J, Flamm SD, Fogel MA, Friedrich MG, et al. Standardized image interpretation and post processing in cardiovascular magnetic resonance: Society for Cardiovascular Magnetic Resonance (SCMR) Board of Trustees Task Force on Standardized Post Processing. J Cardiovasc Magn Res. 2013;15:19.

26. Quail MA, Knight DS, Steeden JA, Taelman L, Moledina S, Taylor AM, et al. Noninvasive pulmonary artery wave intensity analysis in pulmonary hypertension. Am J Physiol Heart Circ Physiol. 2015;308:H1603-11. 
27. Mooij CF, de Wit CJ, Graham DA, Powell AJ, Geva T. Reproducibility of MRI measurements of right ventricular size and function in patients with normal and dilated ventricles. J Magn Reson Imaging. 2008;28:67-73.

28. Naeije R, Manes A. The right ventricle in pulmonary arterial hypertension. Eur Respir Rev. 2014;23:476-87.

29. Vanderpool RR, Desai AA, Knapp SM, Simon MA, Abidov A, Yuan JX, et al. How prostacyclin therapy improves right ventricular function in pulmonary arterial hypertension. Eur Respir J. 2017;50(2).

30. Vanderpool RR, Rischard F, Naeije R, Hunter K, Simon MA. Simple functional imaging of the right ventricle in pulmonary hypertension: can right ventricular ejection fraction be improved? Int J Cardiol. 2016;223:93-4.

31. Kang KW, Chang HJ, Kim YJ, Choi BW, Lee HS, Yang WI, et al. Cardiac magnetic resonance imaging-derived pulmonary artery distensibility index correlates with pulmonary artery stiffness and predicts functional capacity in patients with pulmonary arterial hypertension. Circ J. 2011;75:2244-51.
32. Sanz J, Kuschnir P, Rius T, Salguero R, Sulica R, Einstein AJ, et al. Pulmonary arterial hypertension: noninvasive detection with phase-contrast MR imaging. Radiology. 2007;243:70-9.

33. Laffon E, Bernard V, Montaudon M, Marthan R, Barat JL, Laurent F. Tuning of pulmonary arterial circulation evidenced by MR phase mapping in healthy volunteers. J Appl Physiol. 2001;90:469-74.

34. Cagini L, Andolfi M, Leli C, Potenza R, Ragusa M, Scarnecchia E, et al. B-type natriuretic peptide following thoracic surgery: a predictor of postoperative cardiopulmonary complications. Eur J Cardiothorac Surg. 2014;46:E74-80.

35. Miyazawa M, Haniuda M, Nishimura H, Kubo K, Amano J. Longterm effects of pulmonary resection on cardiopulmonary function. J Am Coll Surg. 1999;189:26-33.

Key Words: right ventricular function, lung resection, cardiovascular magnetic resonance 


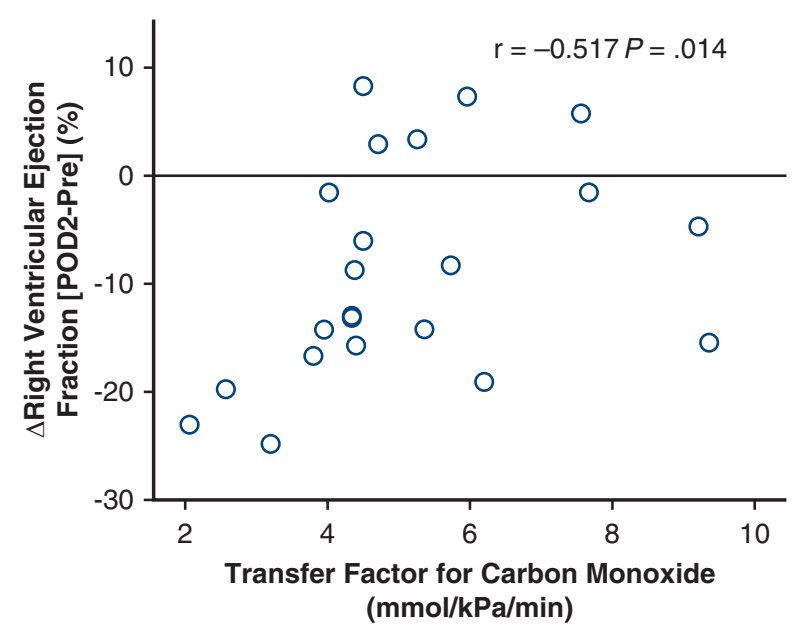

FIGURE E1. Moderate positive association between transfer factor for carbon monoxide and change in right ventricular ejection fraction from preoperative to POD2 ( $\triangle \mathrm{RVEF}$ [POD2-Pre]) (Pearson correlation coefficient). POD 2, Postoperative day 2.

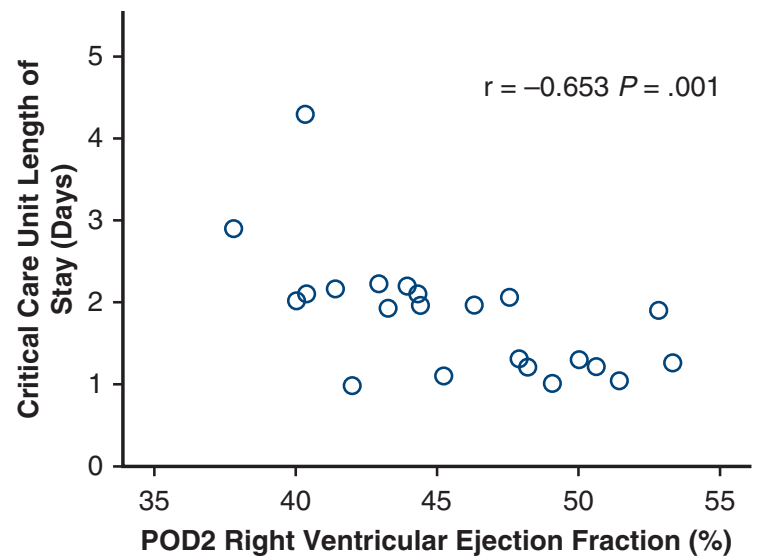

FIGURE E2. Moderate positive association between right ventricular ejection fraction on postoperative day 2 (POD2) and duration of critical care unit length of stay (Spearman $\mathrm{v}$ correlation coefficient). 
TABLE E1. Patient characteristics by follow-up group

\begin{tabular}{|c|c|c|}
\hline Characteristic & Complete $(n=20)$ & Incomplete $(n=7)$ \\
\hline \multicolumn{3}{|l|}{ Patient characteristics } \\
\hline Age (y) & $64.0(58.0,75.0)$ & $69(59,73)$ \\
\hline Female sex & $12(60.0)$ & $5(71.4)$ \\
\hline \multicolumn{3}{|l|}{ Smoking } \\
\hline None & $2(10.0)$ & 0 \\
\hline Former & $6(30.0)$ & $6(85.7)$ \\
\hline Active & $12(60.0)$ & $1(14.3)$ \\
\hline \multicolumn{3}{|l|}{ Preoperative pulmonary function } \\
\hline $\mathrm{SaO}_{2}$ on air $(\%)$ & $96.5(1.7)$ & $95.9(1.7)$ \\
\hline $\mathrm{FEV}_{1}(\mathrm{~L})$ & $1.9(1.7,2.6)$ & $1.7(1.6,2.0)$ \\
\hline$\%$ Predicted $\mathrm{FEV}_{1}(\%)$ & $89.2(28.4)$ & $83.0(13.3)$ \\
\hline $\mathrm{FEV}_{1}$ to $\mathrm{FVC}$ ratio $(\%)$ & $63.5(14.9)$ & $68.4(13.9)$ \\
\hline $\mathrm{TLCO}(\mathrm{mL} / \mathrm{kPa} / \mathrm{min})$ & $5.2(1.8)$ & $5.4(1.2)$ \\
\hline$\%$ Predicted TLCO $(\%)$ & $66.4(15.2)$ & $72.3(7.8)$ \\
\hline \multicolumn{3}{|l|}{ Operative variables } \\
\hline Pneumonectomy & $1(5.0)$ & 0 \\
\hline Lobectomy & $17(85.0)$ & $5(71.4)$ \\
\hline Bilobectomy & $2(10.0)$ & $2(28.6)$ \\
\hline Right-sided procedure & $12(60.0)$ & $5(71.4)$ \\
\hline Segments resected $(\mathrm{n})$ & $5(3,5)$ & $5(3,5)$ \\
\hline Duration of surgery (min) & $128.0(113.3,155.3)$ & $169.0(146.0,201.0)$ \\
\hline Duration of OLV (min) & $53.0(44.0,64.5)$ & $84.0(56.0,108.0)$ \\
\hline Intra-op fluid administration $(\mathrm{mL})$ & $935.0(429.5)$ & $928.6(345.0)$ \\
\hline \multicolumn{3}{|l|}{ Pathology } \\
\hline Primary lung cancer & $17(85.0 \%)$ & $7(100.0 \%)$ \\
\hline Metastatic malignancy & $1(5.0 \%)$ & 0 \\
\hline Benign & $2(10.0 \%)$ & 0 \\
\hline \multicolumn{3}{|l|}{ Comorbidities* } \\
\hline History of cancer & $7(35.0)$ & 0 \\
\hline COPD & $4(20.0)$ & $2(28.6)$ \\
\hline Hypertension & $4(20.0)$ & $5(71.4)$ \\
\hline Ischemic heart disease & $4(20.0)$ & $2(28.6)$ \\
\hline Diabetes mellitus & 0 & 0 \\
\hline Peripheral vascular disease & $2(10.0)$ & $3(42.9)$ \\
\hline Obesity & $1(5.0)$ & $1(14.3)$ \\
\hline Alcoholism & 0 & 0 \\
\hline Thoracic Surgery Scoring System (\%) & $0.7(0.5,0.8)$ & $0.6(0.4,1.0)$ \\
\hline Critical care unit length of stay (h) & $46.7(29.1,51.6)$ & $70.4(31.5,72.0)$ \\
\hline Hospital length of stay (d) & $8(7.0,10.8)$ & $9(8.0,11.0)$ \\
\hline
\end{tabular}

Data are presented as mean \pm standard deviation, $\mathrm{n} \%$ ), or median (interquartile range). $\mathrm{SaO}_{2}$, Oxygen saturation; $F E V_{l}$, forced expiratory volume in 1 second; $F V C$, forced vital capacity; $T L C O$, transfer factor for carbon monoxide; $O L V$, one-lung ventilation; $C O P D$, chronic obstructive pulmonary disease. *Per Thoracic Surgery Scoring System definition of comorbidities. 
TABLE E2. Associations of right ventricle ejection (RVEF) and pulmonary artery acceleration time (PAAT)

\begin{tabular}{|c|c|c|c|c|c|}
\hline \multirow[b]{2}{*}{ Variable } & \multicolumn{5}{|c|}{ RVEF } \\
\hline & Pre & POD2 & 2 months & $\triangle$ POD2-pre & $\Delta 2$ months-pre \\
\hline \multicolumn{6}{|l|}{ PAAT $_{\text {MPA }}$} \\
\hline \multicolumn{6}{|l|}{ Pre } \\
\hline$r$ & -0.100 & & & & \\
\hline$P$ value & .626 & & & & \\
\hline \multicolumn{6}{|l|}{ POD2 } \\
\hline$r$ & & 0.351 & & & \\
\hline$P$ value & & 0.110 & & & \\
\hline \multicolumn{6}{|l|}{2 months } \\
\hline$r$ & & & -0.241 & & \\
\hline$P$ value & & & $.256^{*}$ & & \\
\hline \multicolumn{6}{|c|}{$\triangle \mathrm{PAAT}_{\text {MPA.POD2-pre }}$} \\
\hline$r$ & & & & -0.109 & \\
\hline$P$ value & & & & .648 & \\
\hline \multicolumn{6}{|c|}{$\Delta \mathrm{PAAT}_{\mathrm{MPA} .2 \mathrm{months} \text {-pre }}$} \\
\hline$r$ & & & & & 0.449 \\
\hline$P$ value & & & & & $.047 \dagger$ \\
\hline \multicolumn{6}{|l|}{$\mathrm{PAAT}_{\mathrm{OPA}}$} \\
\hline \multicolumn{6}{|l|}{ Pre } \\
\hline$r$ & -0.222 & & & & \\
\hline$P$ value & .276 & & & & \\
\hline \multicolumn{6}{|l|}{ POD2 } \\
\hline$r$ & & 0.157 & & & \\
\hline$P$ value & & 0.509 & & & \\
\hline \multicolumn{6}{|l|}{2 months } \\
\hline$r$ & & & -0.075 & & \\
\hline$P$ value & & & $.735^{*}$ & & \\
\hline \multicolumn{6}{|c|}{$\triangle \mathrm{PAAT}_{\mathrm{OPA} . \mathrm{POD} 2-\text { pre }}$} \\
\hline$r$ & & & & -0.202 & \\
\hline$P$ value & & & & .422 & \\
\hline \multicolumn{6}{|c|}{$\Delta \mathrm{PAAT}_{\mathrm{OPA} .2 \mathrm{months}-\text { pre }}$} \\
\hline$r$ & & & & & -0.392 \\
\hline$P$ value & & & & & .108 \\
\hline \multicolumn{6}{|l|}{$\mathrm{PAAT}_{\mathrm{NPA}}$} \\
\hline \multicolumn{6}{|l|}{ Pre } \\
\hline$r$ & 0.007 & & & & \\
\hline$P$ value & .974 & & & & \\
\hline \multicolumn{6}{|l|}{ POD2 } \\
\hline$r$ & & 0.488 & & & \\
\hline$P$ value & & .025 & & & \\
\hline \multicolumn{6}{|l|}{2 months } \\
\hline$r$ & & & -0.061 & & \\
\hline$P$ value & & & $.781 *$ & & \\
\hline \multicolumn{6}{|c|}{$\triangle \mathrm{PAAT}_{\mathrm{NPA} . \mathrm{POD} 2-\mathrm{pre}}$} \\
\hline$r$ & & & & 0.231 & \\
\hline$P$ value & & & & .342 & \\
\hline \multicolumn{6}{|c|}{$\Delta \mathrm{PAAT}_{\mathrm{NPA} .2 \mathrm{months}-\mathrm{pre}}$} \\
\hline$r$ & & & & & -0.136 \\
\hline$P$ value & & & & & .580 \\
\hline
\end{tabular}

pre, Preoperative; $P O D$, postoperative day; $\triangle$, change; $O P A$, operative pulmonary artery; NPA, nonoperative pulmonary artery. *Spearman correlation coefficient association; other associations are Pearson correlation coefficient association. Significant associations are highlighted in boldface type. $\dagger P<.05$. 
TABLE E3. Associations of right ventricle ejection (RVEF) and distensibility index (DI)

\begin{tabular}{|c|c|c|c|c|c|}
\hline \multirow[b]{2}{*}{ Variable } & \multicolumn{5}{|c|}{ RVEF } \\
\hline & Pre & POD2 & 2 months & SPOD2-pre & $\Delta 2$ months-pre \\
\hline \multicolumn{6}{|l|}{$\mathrm{DI}_{\mathrm{MPA}}$} \\
\hline \multicolumn{6}{|l|}{ Pre } \\
\hline$r$ & 0.204 & & & & \\
\hline$P$ value & $.316^{*}$ & & & & \\
\hline \multicolumn{6}{|l|}{ POD2 } \\
\hline$r$ & & 0.063 & & & \\
\hline$P$ value & & .780 & & & \\
\hline \multicolumn{6}{|l|}{2 months } \\
\hline$r$ & & & .081 & & \\
\hline$P$ value & & & $.707 *$ & & \\
\hline \multicolumn{6}{|c|}{$\Delta \mathrm{DI}_{\mathrm{MPA} . \mathrm{POD} 2-\mathrm{pre}}$} \\
\hline$r$ & & & & -0.151 & \\
\hline$P$ value & & & & .524 & \\
\hline \multicolumn{6}{|c|}{$\Delta \mathrm{DI}_{\mathrm{MPA}} 2 \mathrm{months-pre}$} \\
\hline$r$ & & & & & 0.311 \\
\hline$P$ value & & & & & .181 \\
\hline \multicolumn{6}{|l|}{$\mathrm{DI}_{\mathrm{OPA}}$} \\
\hline \multicolumn{6}{|l|}{ Pre } \\
\hline$r$ & 0.091 & & & & \\
\hline$P$ value & .656 & & & & \\
\hline \multicolumn{6}{|l|}{ POD2 } \\
\hline$r$ & & -0.143 & & & \\
\hline$P$ value & & .546 & & & \\
\hline \multicolumn{6}{|l|}{2 months } \\
\hline$r$ & & & -0.165 & & \\
\hline$P$ value & & & $.450^{*}$ & & \\
\hline \multicolumn{6}{|c|}{$\Delta \mathrm{DI}_{\mathrm{OPA}} \cdot \mathrm{POD} 2$-pre } \\
\hline$r$ & & & & 0.222 & \\
\hline$P$ value & & & & .375 & \\
\hline \multicolumn{6}{|c|}{$\Delta \mathrm{DI}_{\mathrm{OPA}} 2$ months-pre } \\
\hline$r$ & & & & & 0.203 \\
\hline$P$ value & & & & & .419 \\
\hline \multicolumn{6}{|l|}{$\mathrm{DI}_{\mathrm{NPA}}$} \\
\hline \multicolumn{6}{|l|}{ Pre } \\
\hline$r$ & 0.157 & & & & \\
\hline$P$ value & .444 & & & & \\
\hline \multicolumn{6}{|l|}{ POD2 } \\
\hline$r$ & & 0.309 & & & \\
\hline$P$ value & & .173 & & & \\
\hline \multicolumn{6}{|l|}{2 months } \\
\hline$r$ & & & -0.180 & & \\
\hline$P$ value & & & $.410^{*}$ & & \\
\hline \multicolumn{6}{|c|}{$\Delta \mathrm{DI}_{\mathrm{NPA}} \cdot \mathrm{POD} 2-\mathrm{pre}$} \\
\hline$r$ & & & & 0.319 & \\
\hline$P$ value & & & & $.183^{*}$ & \\
\hline \multicolumn{6}{|c|}{$\Delta \mathrm{DI}_{\mathrm{NPA}} 2$ months-pre } \\
\hline$r$ & & & & & 0.039 \\
\hline$P$ value & & & & & .873 \\
\hline
\end{tabular}

$R V E F$, Right ventricle ejection; $D I$, distensibility index; Pre, preoperative; $P O D$, postoperative day; $\triangle$, change; $O P A$, operative pulmonary artery; $N P A$, nonoperative pulmonary artery. *Spearman correlation coefficient association; other associations are Pearson correlation coefficient association. 
TABLE E4. Associations of right ventricular ejection fraction (RVEF) and change $(\Delta)$ in RVEF with biomarkers of myocardial dysfunction

\begin{tabular}{|c|c|c|c|c|c|}
\hline \multirow[b]{2}{*}{ Biomarker } & \multicolumn{3}{|c|}{ RVEF } & \multicolumn{2}{|c|}{ ARVEF } \\
\hline & Pre & POD2 & 2 months & POD2-pre & 2 months-pre \\
\hline \multicolumn{6}{|l|}{$\mathrm{BNP}_{\text {pre }}$} \\
\hline$r$ & -0.050 & -0.127 & 0.529 & 0.159 & 0.275 \\
\hline$P$ value & .810 & .572 & $.008 *$ & .481 & .205 \\
\hline \multicolumn{6}{|l|}{$\mathrm{BNP}_{\mathrm{POD} 2}$} \\
\hline$r$ & & -0.462 & 0.212 & -0.490 & -0.000 \\
\hline$P$ value & & .030 & .319 & $.021 \dagger$ & .998 \\
\hline \multicolumn{6}{|l|}{$\mathrm{BNP}_{2 \text { months }}$} \\
\hline$R$ & & & 0.378 & & 0.021 \\
\hline$P$ value & & & .076 & & .926 \\
\hline \multicolumn{6}{|l|}{ Trop pre } \\
\hline$r$ & -0.077 & 0.078 & 0.090 & 0.235 & -0.109 \\
\hline$P$ value & .713 & .728 & .676 & .291 & .620 \\
\hline \multicolumn{6}{|l|}{ Trop } \\
\hline$r$ & & -0.129 & 0.187 & -0.140 & -0.005 \\
\hline$P$ value & & .579 & .394 & .544 & .982 \\
\hline \multicolumn{6}{|l|}{ Trop $_{2 \text { months }}$} \\
\hline$r$ & & & -0.035 & & -0.123 \\
\hline$P$ value & & & .880 & & .605 \\
\hline
\end{tabular}

All associations are Pearson correlation coefficient. Significant associations are highlighted in boldface type. $R V E F$, Right ventricle ejection; Pre, immediately preoperative; post immediately postoperative; $P O D$, postoperative day; $B N P$, B-type natriuretic peptide; Trop, high-sensitivity-troponin $\mathrm{T}$. $* P<.01$. $\dagger P<.05$. 